\title{
TESTES FISIOLÓGICOS E BIOQUÍMICOS NA ESTIMATIVA DO POTENCIAL DE ARMAZENAMENTO DE SEMENTES DE ALGODÃ ${ }^{1}$
}

\author{
RAQUEL ALVES DE FREITAS ${ }^{2}$; DENISE CUNHA FERNANDES DOS SANTOS DIAS ${ }^{3}$; \\ LUIZ ANTÔNIO DOS SANTOS DIAS ${ }^{4}$; MARIA GORETI DE ALMEIDA OLIVEIRA ${ }^{3}$
}

\begin{abstract}
RESUMO- A pesquisa teve por objetivo avaliar a eficiência de testes de vigor e de determinações bioquímicas em estimar o potencial de conservação de sementes de algodão (Gossypium hirsutum L.) durante o armazenamento por doze meses, em câmara fria e em condições de ambiente no Setor de Armazenamento do Departamento de Fitotecnia da UFV. Antes do armazenamento, as sementes foram submetidas aos seguintes testes e determinações: germinação, envelhecimento acelerado, germinação a baixa temperatura, emergência das plântulas em leito de areia, condutividade elétrica, teor de lipídios e atividades de lipoxigenase, fosfatase ácida e inibidor de tripsina. Para estimar o potencial de armazenamento, aplicou-se uma análise das distâncias generalizadas de Mahalanobis entre os resultados obtidos nos testes de vigor e nas determinações bioquímicas realizadas antes do armazenamento e os percentuais de germinação obtidos a cada dois meses de armazenamento. Os testes de envelhecimento acelerado e de germinação a baixa temperatura, realizados antes do armazenamento, podem ser utilizados para estimar a viabilidade das sementes, respectivamente, após oito e dez meses de armazenamento em ambiente. $\mathrm{O}$ teste de condutividade elétrica e as determinações bioquímicas não permitem prever o potencial de armazenamento das sementes de algodão.
\end{abstract}

Termos para indexação: Gossypium hirsutum, conservação, vigor, determinações bioquímicas.

\section{PHYSIOLOGICAL AND BIOCHEMICAL TESTS TO ESTIMATE OF STORAGE POTENTIAL OF COTTON SEEDS}

\begin{abstract}
The objective of this study was to evaluate the efficiency of vigour tests and biochemical determinations to estimate the storage potential of cotton seeds (Gossypium hirsutum L.) during 12 months of storage in a cold chamber and environmental conditions in the Storage Sector at the Plant Pathology Department of the Federal University of Viçosa. Before storage, the seeds were submitted to the following tests and determinations: germination, accelerated aging, cool germination, seedling emergence in sand, electric conductivity, lipids content and activities of the lipoxygenase, acid phosphatase and trypsin inhibitors. Aiming to estimate the storage potential, an analysis of the generalized Mahalanobis distances was applied on the results obtained in the vigour tests and on the biochemical determinations carried out before storage and the percentages of germination obtained from each two months of storage. The accelerated aging and cool germination tests carried out before storage can be used to estimate the viability of the seeds, respectively, after eight and ten months of storage under environment conditions. The electric conductivity test and biochemical determinations did not allow estimation of the storage potential of cotton seeds.
\end{abstract}

Index terms: Gossypium hirsutum, storage, vigour, biochemical determinations.

\section{INTRODUÇÃO}

\footnotetext{
${ }^{1}$ Submetido em 22/08/2003. Aceito para publicação em 10/02/2004. Parte integrante da tese de doutorado da primeira autora em Agronomia/Fitotecnia da Universidade Federal de Viçosa (UFV).

2 Bolsista Recém Doutor/CNPq, Universidade Federal de Uberlândia, Cx. Postal 593, 38400-902, Uberlândia-MG, freitasra@yahoo.com.br.

3 Prof $f^{\text {as }}$ dos Departamentos de Fitotecnia e Bioquímica, UFV, 36571-000, Viçosa-MG, dcdias@ufv.br.

${ }^{4}$ Pesquisador do BIOAGRO/UFV, lasdias@ufv.br.
}

A manutenção da qualidade da semente durante o período de armazenamento é um aspecto a ser considerado dentro do processo produtivo de qualquer cultura, visto que o sucesso de uma lavoura depende, principalmente, da utilização de sementes com alto padrão de qualidade.

Segundo Carvalho \& Nakagawa (2000), no armazenamento, a velocidade do processo deteriorativo pode ser controlada em função da longevidade, da 
qualidade inicial das sementes e das condições do ambiente. Como a longevidade é uma característica genética inerente à espécie, somente a qualidade inicial das sementes e as condições do ambiente de armazenamento podem ser manipuladas.

Durante o armazenamento de sementes de algodoeiro, em dois ambientes (câmara fria e condições não controladas), Medeiros Filho et al. (1996) observaram que, quando as sementes foram armazenadas em ambiente sem controle de temperatura e umidade relativa, ocorreu redução significativa da germinação e do vigor, durante um período de quatro meses.

Estudos conduzidos por Paolinelli \& Braga (1997), avaliando alterações na qualidade de sementes de algodoeiro durante o armazenamento, mostraram interações altamente significativas entre níveis de vigor da semente e períodos de armazenamento. Para o lote de vigor alto, não houve diferenças entre condições de armazenamento por até cinco meses. Após esse período, aos 10 meses, a qualidade das sementes armazenadas em condições de ambiente decresceu drasticamente. Por outro lado, os lotes armazenados em câmara fria foram estatisticamente superiores e mantiveram a germinação, quando comparados àqueles mantidos em condições de ambiente. Também com sementes de algodão, Pádua \& Vieira (2001) e Pádua et al. (2002) observaram que lotes de baixo vigor apresentaram menor tolerância ao armazenamento.

Pádua et al. (2002) armazenaram sementes de algodão com diferentes níveis de vigor em condição ambiente e verificaram que a qualidade das sementes foi mantida até o oitavo mês de armazenamento, sendo que a redução da qualidade foi associada ao aumento na ocorrência de Aspergillus sp. e Penicillium sp. nas sementes. Freitas et al. (2000) também já haviam constatado aumento da incidência destes fungos no decorrer do armazenamento, observando, ainda, decréscimo da viabilidade e do vigor das sementes de algodão.

Pelo exame da literatura verifica-se que, na última década, diversos estudos sobre armazenamento de sementes de algodão vêm sendo realizados. No entanto, são escassos os trabalhos que buscam avaliar alterações bioquímicas decorrentes do armazenamento destas sementes.

Apesar de os mecanismos que levam à deterioração da semente ainda não estarem completamente elucidados, sabe-se que a redução na qualidade fisiológica das sementes está relacionada a alterações bioquímicas que conduzem ao comprometimento de suas atividades metabólicas. Dentre estas alterações, destacam-se: mudanças na atividade respiratória e enzimática, nos processos de síntese, nos compostos de reserva, nas membranas celulares e nos cromossomos (Abdul-Baki \& Anderson, 1972 e McDonald Jr., 1999).

Considerando que o principal desafio das pesquisas sobre vigor de sementes está na identificação de características que permitam avaliar precocemente o processo de deterioração, o monitoramento destas alterações pode se constituir em ferramenta eficiente para a avaliação da qualidade das sementes. Segundo Copeland \& McDonald Jr. (1985), para detectar o início da deterioração, as avaliações mais sensíveis são aquelas relacionadas à atividade de enzimas associadas à biossíntese em tecidos novos. Neste sentido, pesquisas têm sido conduzidas buscando determinar alterações na atividade de determinadas enzimas associando-as à perda de qualidade da semente.

Dessa forma, objetivou-se avaliar a eficiência de testes fisiológicos e bioquímicos na estimativa do potencial de armazenamento das sementes de algodão.

\section{MATERIAL E MÉTODOS}

O trabalho foi conduzido nos Laboratórios de Sementes e de Bioquímica da Universidade Federal de Viçosa (UFV). Foram utilizadas sementes de algodão (Gossypium hirsutum L.), deslintadas quimicamente, das variedades IAC-20 RR e Fabrika, fornecidas pela empresa Syngenta, as quais foram submetidas aos seguintes testes:

Germinação - conduzido com oito subamostras de 25 sementes, em rolo de papel germitest, umedecido com água, na proporção de 2,5 vezes o peso do papel seco, em germinador a $25^{\circ} \mathrm{C}$. Foram realizadas contagens aos quatro e sete dias após a instalação do teste e as avaliações feitas conforme critérios estabelecidos pelas Regras para Análise de Sementes (Brasil, 1992);

Envelhecimento acelerado - utilizou-se a metodologia proposta pela AOSA (1983) e descrita por Marcos-Filho (1999). Foram distribuídas 200 sementes sobre uma tela de alumínio, fixada em caixa plástica tipo "gerbox", contendo ao fundo, $40 \mathrm{ml}$ de água. As caixas contendo as sementes, foram fechadas e mantidas em incubadora BOD a $42^{\circ} \mathrm{C}$, por 72 horas. Após esse período, as sementes foram submetidas ao teste de germinação. A avaliação da porcentagem de plântulas normais foi realizada aos quatro dias após a instalação do teste;

Germinação a baixa temperatura - adotou-se a metodologia recomendada pela AOSA (1983) e descrita por Dias \& Alvarenga (1999). Conduzido com quatro subamostras de 50 sementes, adotando o mesmo procedimento descrito para o teste de germinação, sendo que os rolos foram acondicionados em sacos plásticos e mantidos em incubadora BOD a $18^{\circ} \mathrm{C}$, no escuro. A avaliação foi feita oito dias após a instalação do teste, sendo computada a porcentagem de plântulas normais que apresentavam comprimento do eixo hipocótilo-radícula maior ou igual a $4,0 \mathrm{~cm}$;

Condutividade elétrica - quatro subamostras de 50 sementes foram pesadas com precisão de três casas decimais e, posteriormente, colocadas em copos plásticos contendo $75 \mathrm{ml}$ de água destilada e mantidos em incubadora 
BOD a $25^{\circ} \mathrm{C}$, por 24 horas. Após esse período, a condutividade elétrica da solução foi determinada em condutivímetro e os resultados foram expressos em $\mu \mathrm{S} \mathrm{cm}^{-1}$ $\mathrm{g}^{-1}$ de semente (Vieira \& Krzyzanowski, 1999);

Emergência das plântulas em leito de areia - foi realizada em caixas plásticas contendo areia peneirada e esterilizada com brometo de metila, utilizando-se quatro subamostras de 50 sementes. Em cada caixa foram semeadas 50 sementes por sulco à profundidade de $2 \mathrm{~cm}$, num total de quatro sulcos por caixa. Irrigações foram efetuadas sempre que necessário. A avaliação da porcentagem de emergência de plântulas foi efetuada aos dez dias após a semeadura;

Determinação da atividade de lipoxigenase - para obtenção do extrato, as sementes foram maceradas em almofariz em banho de gelo, utilizando tampão fosfato de sódio $50 \mathrm{mM}$, pH 6,5, na proporção 1:10 (p/v). Posteriormente, o extrato foi centrifugado a $17.200 \mathrm{~g}$ por 30 minutos, a $4^{\circ} \mathrm{C}$. O sobrenadante foi utilizado para determinação da atividade de lipoxigenase e de proteína. A concentração de proteína foi determinada pelo método do ácido bicinconínico desenvolvido por Smith et al. (1985). A atividade de lipoxigenase sobre o ácido linoléico foi determinada segundo o método descrito por Axelrod et al. (1981). Para tanto, misturaram-se $1,0 \mu \mathrm{L}$ do extrato e 4,0 $\mu \mathrm{L}$ de uma solução-estoque de linoleato de sódio $10 \mathrm{mM}$ em 1,0 mL de tampão fosfato de sódio $0,05 \mathrm{M}, \mathrm{pH} \mathrm{5,0} \mathrm{a}$ $25^{\circ} \mathrm{C}$, de acordo com os resultados de experimentos preliminares. A absorvância da mistura de reação foi determinada de 15 em 15 segundos, a $234 \mathrm{~nm}$, por um período de 2,5 minutos. $\mathrm{O}$ mesmo procedimento foi usado para o branco, o qual não continha o extrato da semente. As velocidades iniciais, obtidas pela medida de absorção a 234 $\mathrm{nm}$, em função do tempo, foram determinadas utilizando-se o coeficiente de extinção molar de $25.000 \mathrm{M}^{-1} \mathrm{~cm}^{-1}$ para o produto formado. Todas as incubações foram feitas em triplicatas;

Determinação da atividade de fosfatase ácida para obtenção do extrato, uma semente foi macerada em almofariz em banho de gelo, utilizando tampão acetato de potássio $0,1 \mathrm{M}, \mathrm{pH} 5,0$, na proporção 1:10 (p/v). Posteriormente, centrifugado a $24.700 \mathrm{~g}$ por 15 minutos, a $4^{\circ} \mathrm{C}$. O sobrenadante foi utilizado para determinação da atividade de fosfatase ácida, a qual foi determinada seguindo a metodologia descrita por Maia et al. (2000). Para tanto, $50 \mu \mathrm{L}$ do extrato foi adicionado a uma mistura contendo $100 \mu \mathrm{L}$ do substrato p-nitrofenil fosfato $0,018 \mathrm{M} \mathrm{e}$ $800 \mu \mathrm{L}$ do tampão acetato de potássio $0,1 \mathrm{M}, \mathrm{pH} 5,0$. Os tubos foram incubados a $30^{\circ} \mathrm{C}$ por 5 minutos. Posteriormente, adicionou-se um $\mathrm{mL}$ de hidróxido de sódio 0,5 M e procedeu-se a leitura em espectrofotômetro a 400 $\mathrm{nm}$, após o branco $(1 \mathrm{~mL}$ da solução tampão e $2 \mathrm{~mL}$ de água destilada). Os resultados foram expressos em unidades de absorvância a $400 \mathrm{~nm} \mathrm{~min}{ }^{-1} \mathrm{mg}^{-1}$ de semente. Todas as análises foram feitas em triplicata;

Determinação de inibidores de protease - para obtenção do extrato, as sementes foram maceradas em almofariz em banho de gelo, utilizando tampão Tris- $\mathrm{HCl}$ $0,1 \mathrm{M}, \mathrm{pH} 8,2$, contendo $20 \mathrm{mM}$ de $\mathrm{CaCl}_{2}$, na proporção $1: 10(\mathrm{p} / \mathrm{v})$. O homogenato foi centrifugado a $17.200 \mathrm{~g}$ por 30 minutos, a $4{ }^{\circ} \mathrm{C}$. A presença de inibidores de proteases foi determinada utilizando-se tripsina bovina. A atividade tríptica, na presença ou na ausência de inibidores, consistiu no seguinte procedimento analítico: para a análise do teste, $100 \mu \mathrm{L}$ do extrato; $500 \mu \mathrm{L}$ de Tris- $\mathrm{HCl} 0,1 \mathrm{M}, \mathrm{pH} \mathrm{8,2,}$ contendo $20 \mathrm{mM}$ de $\mathrm{CaCl}_{2}$; e, $50 \mu \mathrm{L}$ da solução de tripsina $4,7 \times 10^{-5} \mathrm{M}$ foram adicionados em um tubo de ensaio. Para o controle da enzima, foram adicionados, num outro tubo de ensaio, $600 \mu \mathrm{L}$ de Tris- $\mathrm{HCl} 0,1 \mathrm{M}, \mathrm{pH} 8,2$, contendo 20 $\mathrm{mM}$ de $\mathrm{CaCl}_{2} ; 50 \mu \mathrm{L}$ da solução de tripsina $4,7 \times 10^{-5} \mathrm{M}$. Essa mistura contida em ambos os tubos (teste e controle da enzima, respectivamente) foi incubada por cinco minutos, à temperatura ambiente. Após este tempo, foram retirados $500 \mu \mathrm{L}$ da mistura de incubação, do teste e do respectivo controle e adicionados a outro tubo com $500 \mu \mathrm{L}$ de Tris$\mathrm{HCl}$ 0,1 M, pH 8,2, contendo $20 \mathrm{mM}$ de $\mathrm{CaCl}_{2}$ e $500 \mu \mathrm{L}$ da solução de D,L-BApNA 1,2 mM. A absorvância da solução foi determinada a $410 \mathrm{~nm}$ durante 2,5 minutos de reação. As análises foram feitas em triplicatas. Os resultados obtidos foram convertidos em $\mathrm{mg}$ de tripsina inibida por grama de proteína, de acordo com a seguinte equação:

$$
\mathrm{mg} \text { de tripsina inibida } \mathrm{g}^{-1} \text { de proteína }=\frac{\mathrm{AxB}}{\mathrm{Cx} 1.000 \times \mathrm{P}},
$$
sendo:

A = Absorvância a $410 \mathrm{~nm}$ do padrão - Absorvância a $410 \mathrm{~nm}$ da amostra;

$\mathrm{B}=$ Diluição da amostra;

$\mathrm{P}=$ Concentração, em $\mathrm{g} \mathrm{mL}^{-1}$, de proteína do extrato;

e

$\mathrm{C}=$ Fator de tripsina, ou seja, o produto da atuação de $1 \mu \mathrm{g}$ de tripsina ativa sobre o substrato D,L-BApNa dá uma leitura de absorvância em $410 \mathrm{~nm}$ de 0,019 (Kakade et al., 1974).

Determinação de lipídios - foi realizada em aparelho extrator de Soxhlet, utilizando éter de petróleo como solvente, segundo o procedimento descrito em Normas Analíticas do Instituto Adolfo Lutz (INSTITUTO ADOLFO LUTZ, 1985), com refluxo por 24 horas.

Após a realização dos testes, as sementes foram acondicionadas em embalagens permeáveis (sacos de papel), sendo que uma metade $(5 \mathrm{~kg})$ foi armazenada em câmara fria $(\mathrm{CF})$, à temperatura de $10 \pm 2^{\circ} \mathrm{C}$ e umidade relativa do ar de $70 \pm 5 \%$ e a outra metade $(5 \mathrm{~kg})$ em condições ambiente (Amb) no Setor de Armazenamento da Unidade de Beneficiamento de Sementes do Departamento de Fitotecnia da UFV. Tanto em câmara fria como em 
ambiente, as sementes permaneceram armazenadas durante 12 meses. A cada dois meses, eram retiradas amostras para a realização de testes de germinação, conforme metodologia descrita anteriormente. Os dados das temperaturas máxima e mínima e da umidade relativa do ar média registrados em condição ambiente estão apresentados nas Figuras 1 e 2.

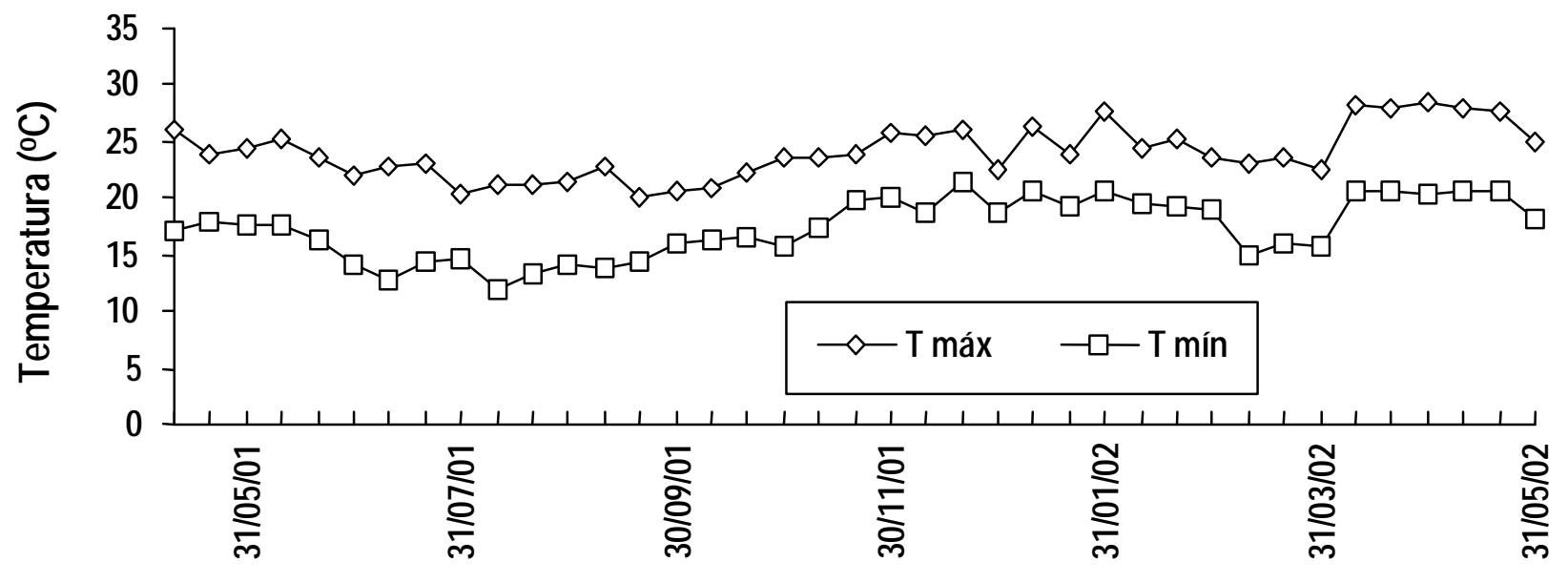

Período de Armazenamento

FIGURA 1. Dados médios, em decêndios, de temperatura máxima e mínima, registrados no Departamento de Fitotecnia da Universidade Federal de Viçosa, durante o período de armazenamento das sementes. Viçosa-UFV/2001-2002

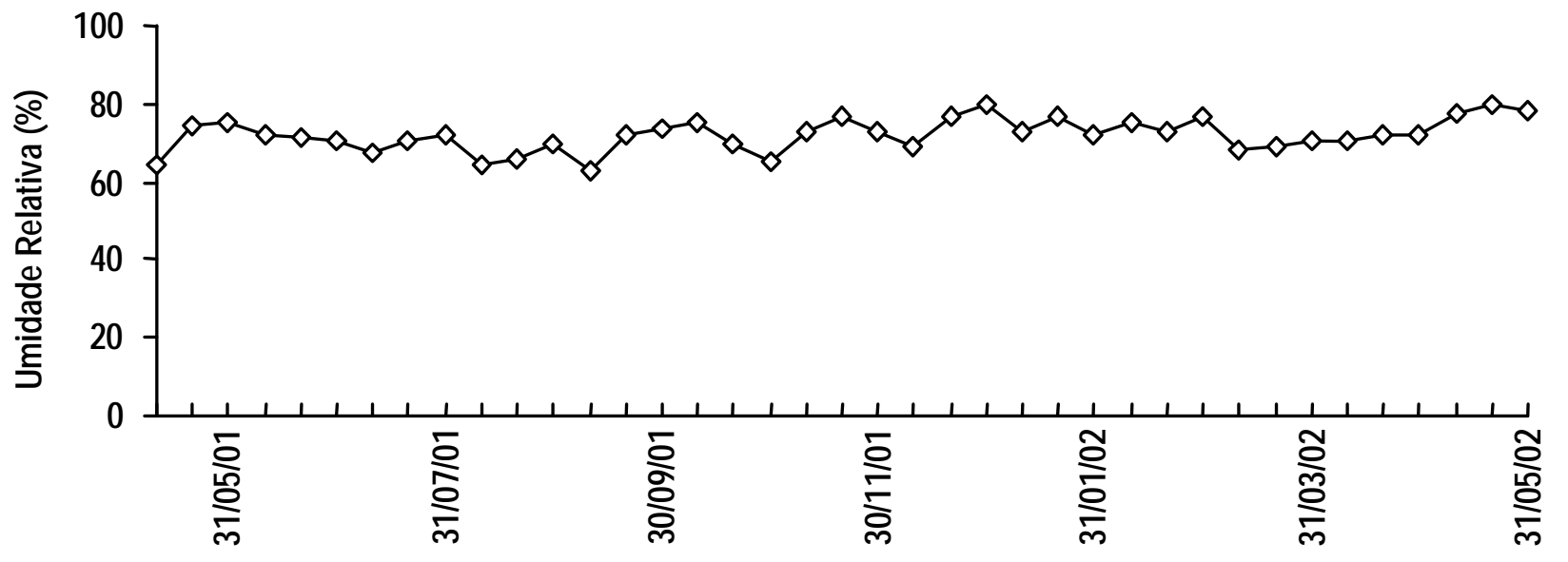

Período de Armazenamento

FIGURA 2. Dados médios, em decêndios, de umidade relativa do ar média, registrados no Departamento de Fitotecnia da Universidade Federal de Viçosa, durante o período de armazenamento das sementes. Viçosa-UFV/2001-2002

O experimento foi conduzido no delineamento inteiramente casualizado, com quatro repetições e analisado num esquema de parcelas subdivididas. As variedades (Fabrika e IAC-20 RR) e as condições de armazenamento (ambiente e câmara fria) foram alocadas em esquema fatorial nas parcelas e os períodos de armazenamento $(0,2$, 4, 6, 8, 10 e 12 meses) nas subparcelas. Para estimar o potencial de armazenamento das sementes, foi aplicada uma análise das distâncias generalizadas de Mahalanobis (1936) entre os resultados obtidos nos testes de vigor e nas determinações bioquímicas, realizadas antes do armazenamento, relacionando estes resultados aos percentuais de germinação obtidos em cada período de armazenamento. $\mathrm{O}$ procedimento consistiu do seguinte:

Considerou-se $X_{\mathrm{ijk}}$ a observação referente ao jésimo arranjo do fatorial alocado na parcela $(\mathrm{j}=1,2, \ldots, 4)$ no 
i-ésimo teste $(i=1,2, \ldots, 15)$ e na k-ésima repetição $(\mathrm{K}=1,2,3,4)$. A partir dessas observações, foram estimadas as médias $\mathrm{X}_{\mathrm{ij}}\left(\mathrm{X}_{\mathrm{ij}} / \mathrm{k}\right)$, a matriz de variância e covariâncias residuais e os desvios $\left(\mathrm{d}_{\mathrm{j}}\right)$, sendo:

$$
\begin{aligned}
& \mathrm{d}_{1=} \mathrm{X}_{\mathrm{i} 1^{-}}-\mathrm{X}_{\mathrm{i}^{\prime} 1} ; \\
& \mathrm{d}_{2=} \mathrm{X}_{\mathrm{i} 2^{2}}-\mathrm{X}_{\mathrm{i} 2} ; \\
& \ldots \ldots . . \\
& \mathrm{d}_{4=} \mathrm{X}_{\mathrm{i} 4^{-}} \mathrm{X}_{\mathrm{i}^{\prime} 4 .} \\
& \text { Assim, } \mathrm{D}_{\mathrm{ii}}{ }^{2}=\delta^{\prime} \Psi^{-1} \delta, \text { em que: }
\end{aligned}
$$

$\mathrm{D}_{\mathrm{ii}}{ }^{2}$ é a distância generalizada de Mahalanobis entre o iésimo teste de vigor ou determinação bioquímica e o iésimo percentual de germinação, no i-ésimo período de armazenamento;

$\delta^{\prime}=\left[\mathrm{d}_{1} \mathrm{~d}_{2} \mathrm{~d}_{3} \mathrm{~d}_{4}\right] ; \mathrm{e}$

$\Psi=$ matriz de variância e covariâncias residuais.

\section{RESULTADOS E DISCUSSÃO}

$\mathrm{Na}$ ausência de efeito isolado de variedade, bem como, da interação com os fatores condições e períodos de armazenamento, no trabalho foram utilizados as médias de cultivares.

Pela Figura 3, verifica-se que enquanto o avanço no período de armazenamento reduziu linearmente o percentual de germinação das sementes armazenadas em ambiente, as que foram mantidas em condições controladas (câmara fria) praticamente não tiveram alteração na germinação. Medeiros Filho et al. (1996) também constataram durante o armazenamento de sementes de algodão, redução significativa da germinação quando as sementes foram armazenadas em ambiente sem controle de temperatura e umidade relativa. Freitas et al. (2000), Pádua \& Vieira (2001) e Pádua et al. (2002) também verificaram que a redução na germinação das sementes de algodão foi mais acentuada com o aumento do período de armazenamento.

Para estimar o potencial de armazenamento, aplicou-se uma análise das distâncias generalizadas de Mahalanobis entre os resultados obtidos nos testes de vigor e nas determinações bioquímicas realizadas antes do armazenamento e os percentuais de germinação obtidos a cada dois meses de armazenamento (Tabela 1). Distâncias não significativas indicam resultados mais concordantes entre os testes.

Dessa forma, verifica-se pelo teste de envelhecimento acelerado que, para as sementes armazenadas em ambiente, distância não significativa foi obtida aos oito meses de armazenamento. Este resultado revela que o percentual de germinação obtido aos oito meses correspondeu ao valor obtido no teste de envelhecimento acelerado realizado antes do armazenamento das sementes. Freitas et al. (2002) armazenando sementes de algodão também em condições ambiente, constataram que o teste de envelhecimento acelerado, realizado antes do armazenamento, estimou a viabilidade das sementes após um período de nove meses de armazenamento. Cabe ressaltar que os referidos autores conduziram o teste de germinação em intervalos de três meses durante um ano. Dessa forma, os resultados obtidos no presente trabalho reforçam os de Freitas et al. (2002), uma vez que, foram utilizados intervalos de dois meses. $\mathrm{O}$ teste de envelhecimento acelerado realizado antes do armazenamento também forneceu uma estimativa do desempenho das sementes de sorgo após um período de 15 meses de armazenamento (Andrade et al. 1994).

Para as sementes armazenadas em câmara fria, o teste de envelhecimento acelerado realizado antes do armazenamento não permitiu estimar a porcentagem de germinação das sementes durante o armazenamento, uma vez que, todas as distâncias mostraram-se significativas (Tabela 1). Dessa forma, verifica-se que, o efeito do estresse provocado pelo teste de envelhecimento acelerado não apresentou concordância com o percentual de germinação das sementes durante o armazenamento em câmara fria.

$\mathrm{O}$ teste de germinação a baixa temperatura apresentou resultados concordantes com o percentual de germinação aos dez e doze meses de armazenamento em ambiente, indicando que este teste quando realizado no início do armazenamento permite estimar o desempenho que as sementes terão no intervalo do décimo ao décimo segundo mês de armazenamento. Já para as sementes armazenadas em câmara fria, à semelhança do teste de envelhecimento acelerado, não foi possível estimar a viabilidade das sementes no período de armazenamento estudado.

Os resultados da emergência das plântulas em leito de areia foram similares aos obtidos no teste de germinação, uma vez que não permitiram estimar o potencial de armazenamento das sementes. Verifica-se que para as sementes mantidas em condição ambiente, distância não significativa foi obtida somente no início do armazenamento (Tabela 1). No entanto, para as sementes armazenadas em câmara fria todos os períodos de armazenamento apresentaram distâncias de Mahalanobis não significativas, indicando que os resultados deste teste quando realizado no início do armazenamento concordam com àqueles obtidos no teste de germinação nos diferentes períodos de armazenamento em câmara fria. Vale ressaltar que as condições da câmara fria permitiram a manutenção da viabilidade das sementes (Figura 3), razão pela qual todas essas distâncias mostraram-se não significativas, sendo, portanto, o teste de emergência das plântulas em leito de areia semelhante ao teste de germinação. 


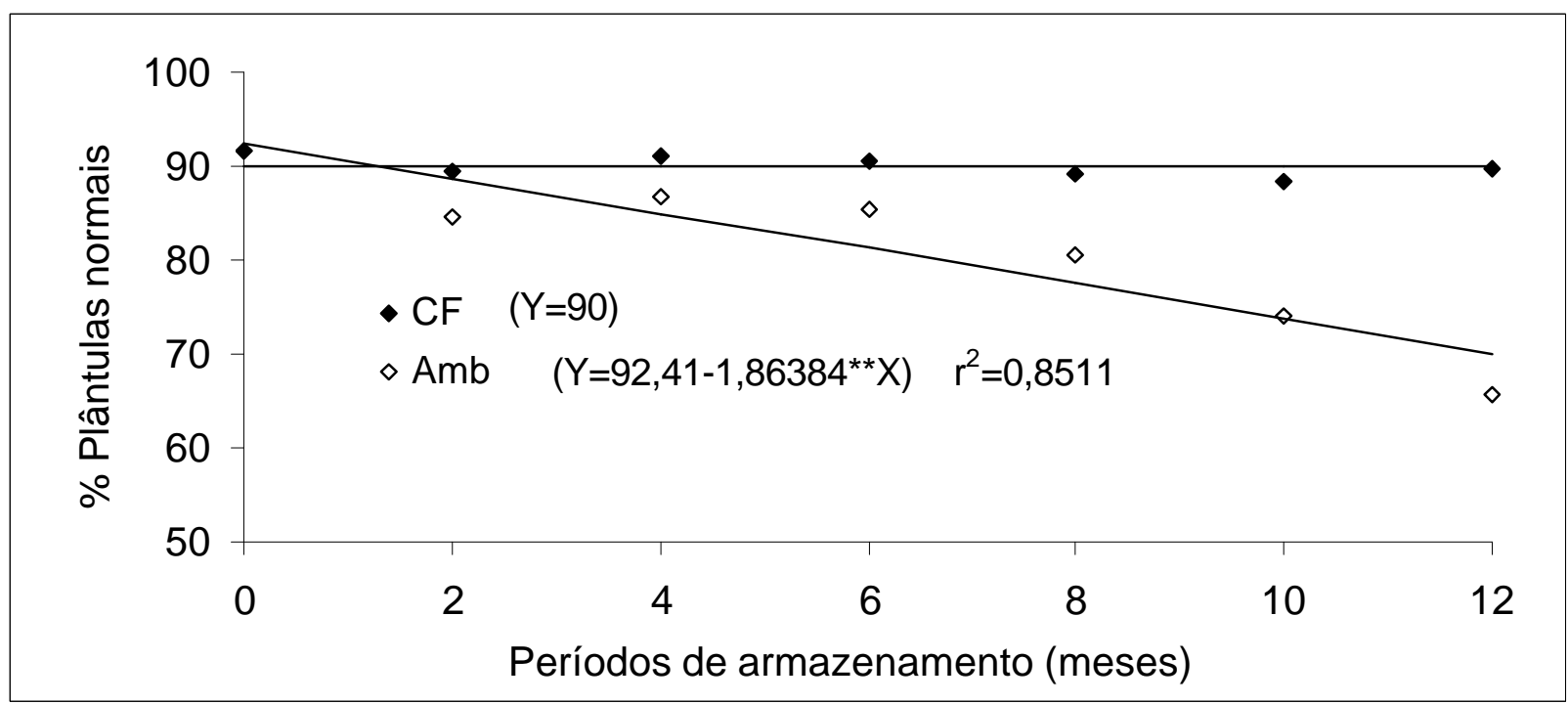

FIGURA 3. Estimativa da porcentagem de plântulas normais obtidas no teste de germinação, em função dos períodos de armazenamento. CF - armazenamento em câmara fria e Amb - armazenamento em ambiente. Viçosa-UFV/2001 - 2002.

TABELA 1. Distâncias generalizadas de Mahalanobis $\left(D^{2}\right)$ entre as porcentagens de germinação obtidas em diferentes períodos de armazenamento e os resultados dos testes de envelhecimento acelerado (EA), germinação a baixa temperatura (GBT), emergência em areia (EMERG), condutividade elétrica (CE), atividades de lipoxigenase (LOX), inibidor de tripsina (IT), fosfatase ácida (FA) e teor de lipídios (LI) realizados antes do armazenamento em ambiente e câmara fria. Viçosa-UFV/2001-2002

\begin{tabular}{|c|c|c|c|c|c|c|c|c|c|}
\hline \multirow{2}{*}{$\begin{array}{l}\text { Condições de } \\
\text { armazenamento }\end{array}$} & \multirow{2}{*}{$\begin{array}{c}\text { Períodos de } \\
\text { armazenamento (meses) }\end{array}$} & \multicolumn{4}{|c|}{ Testes de vigor } & \multicolumn{4}{|c|}{ Determinações bioquímicas } \\
\hline & & $\overline{\mathrm{EA}}$ & $\overline{\text { GBT }}$ & EMERG & $\mathrm{CE}$ & LOX & IT & FA & LI \\
\hline \multirow{7}{*}{ Ambiente } & 0 & $10,5 * *$ & $52,4 * *$ & 0,1 & $360,6^{* *}$ & $706,6 * *$ & $559,3 * *$ & $50,8 * *$ & $496,5 * *$ \\
\hline & 2 & $6,4 * *$ & $26,1 * *$ & $6,8^{* *}$ & $428,5 * *$ & $587,0 * *$ & $453,4 * *$ & $18,8 * *$ & $396,6 * *$ \\
\hline & 4 & $6,1^{* *}$ & $32,9 * *$ & $3,0^{*}$ & $404,8 * *$ & $623,8 * *$ & $485,8 * *$ & $27,3 * *$ & $427,0 * *$ \\
\hline & 6 & $3,4^{*}$ & $27,6 * *$ & $3,4^{*}$ & $426,9 * *$ & $602,8^{* *}$ & $467,3^{* *}$ & $26,4 * *$ & $409,9 * *$ \\
\hline & 8 & 2,8 & $13,3 * *$ & $11,8^{* *}$ & $492,4 * *$ & $524,9 * *$ & $399,0 * *$ & $15,4 * *$ & $346,1 * *$ \\
\hline & 10 & $8,5 * *$ & 1,8 & $30,9 * *$ & $601,8^{* *}$ & $428,2 * *$ & $315,5 * *$ & $14,8 * *$ & $268,9 * *$ \\
\hline & 12 & $31,6^{* *}$ & 2,0 & $69,5 * *$ & $739,7 * *$ & $321,1 * *$ & $224,7 * *$ & $22,0 * *$ & $185,7 * *$ \\
\hline \multirow{7}{*}{ Câmara fria } & 0 & $10,5^{* *}$ & $52,4 * *$ & 0,1 & $360,6^{* *}$ & $706,6^{* *}$ & $559,3 * *$ & $50,8 * *$ & $496,5 * *$ \\
\hline & 2 & $8,1 * *$ & $43,4 * *$ & 0,6 & $376,6 * *$ & $670,8 * *$ & $527,4 * *$ & $39,2 * *$ & $466,2 * *$ \\
\hline & 4 & $10,3 * *$ & $50,1 * *$ & 0,3 & $361,3 * *$ & $697,3 * *$ & $550,9 * *$ & $46,1 * *$ & $488,5 * *$ \\
\hline & 6 & $10,4 * *$ & $48,2 * *$ & 0,8 & $362,2 * *$ & $688,3 * *$ & $542,9 * *$ & $41,8 * *$ & $480,8 * *$ \\
\hline & 8 & $7,5^{* *}$ & $42,2 * *$ & 0,6 & $380,9 * *$ & $666,5^{* *}$ & $523,6 * *$ & $38,9 * *$ & $462,7 * *$ \\
\hline & 10 & $6,1 * *$ & $38,9 * *$ & 0,8 & $391,4 * *$ & $653,6^{* *}$ & $512,1 * *$ & $36,8 * *$ & $451,9 * *$ \\
\hline & 12 & $8,3^{* *}$ & $44,4 * *$ & 0,5 & $374,9 * *$ & $675,2 * *$ & $531,3 * *$ & $40,7 * *$ & $469,9 * *$ \\
\hline
\end{tabular}

$* *$ significativo a $1 \%$ de probabilidade, pelo teste $\mathrm{F}$.

* significativo a $5 \%$ de probabilidade, pelo teste $\mathrm{F}$.

$\mathrm{O}$ teste de condutividade elétrica $\mathrm{e}$ as determinações das atividades de lipoxigenases, fosfatase ácida e inibidor de tripsina e teor de lipídios não permitiram uma estimativa do potencial de armazenamento das sementes nas duas condições de armazenamento. Portanto, os testes de vigor empregados foram mais eficientes para predizer o potencial de armazenamento das sementes de algodão em relação às determinações bioquímicas. Machado Neto et al. (2001) verificaram que características fisiológicas, como germinação e vigor, foram mais eficientes para monitorar a deterioração em sementes de feijão do que as mudanças no padrão de bandas de 
proteínas, No entanto, Vieira (1996) afirmou que estudos de variações eletroforéticas da enzima fosfatase ácida poderiam se constituir em um promissor indicador do estádio deteriorativo das sementes de algodão. Por sua vez, Spinola et al. (2000) verificaram que as alterações das isoenzimas fosfatase ácida e peroxidase foram mais efetivas do que os testes de vigor para avaliar a qualidade das sementes de milho durante a deterioração.

Verifica-se, portanto, que as determinações das atividades de enzimas associadas à degradação e oxidação de substâncias de reserva, realizadas com o objetivo de possibilitar detectar os estádios iniciais do processo de deterioração, não se mostraram eficientes para estimar o potencial de armazenamento das sementes de algodão. Já o efeito deteriorativo provocado pela exposição das sementes a condições de estresse, como acontece nos testes de envelhecimento e de germinação à baixa temperatura, permitiu detectar diferenças na qualidade fisiológica das sementes armazenadas e inferir sobre o seu potencial de armazenamento.

\section{CONCLUSÕES}

Os testes de envelhecimento acelerado e germinação a baixa temperatura, realizados antes do armazenamento, podem ser utilizados para estimar a viabilidade das sementes, respectivamente, após oito e dez meses de armazenamento em ambiente.

$\mathrm{O}$ teste de condutividade elétrica e as determinações bioquímicas realizadas antes do armazenamento não permitem prever o potencial de conservação das sementes de algodoeiro.

\section{REFERÊNCIAS}

ABDUL-BAKI, A.A.; ANDERSON, J.D. Physiological and biochemical deterioration of seeds. In: KOZLOWISKI, T.T. (E.). Seed biology: germination control, metabolism and pathology. New York: Academic Press, 1972, v.2, p.283315 .

ANDRADE, R.V., AZEVEDO, J.T., BORBA, C.S., OLIVEIRA, A.C. Testes de vigor em sementes de sorgo para predizer o armazenamento. Revista Brasileira de Sementes, Brasília,v.16, n.1, p.102-106, 1994.

ASSOCIATION OF OFFICIAL SEED ANALYSTS. Seed vigor testing handbook. Eastasing: AOSA, 1983. 88p. (Contribution, 32).

AXELROD, B., CHEESBROUGH, T.M., LAASKO, S. Lipoxygenases from soybeans. Methods in enzymology, v.71, p.441-451, 1981.

BRASIL. Ministério da Agricultura e Reforma Agrária. Regras para análise de sementes. Brasília: SNDA/DNDV/CLAV, 1992. 365p.

CARVALHO, N.M., NAKAGAWA, J. Sementes: ciência, tecnologia e produção. 4. ed. Jaboticabal: FUNEP, 2000. $588 \mathrm{p}$.

COPELAND, L.O., McDONALD JR., M.B. Principles of seed science and technology. New York: McMillan, 1985. $321 \mathrm{p}$.

DIAS, D.C.F.S., ALVARENGA, E.M. Teste de germinação a baixa temperatura. In: KRZYZANOWSKI, F.C., VIEIRA, R.D., FRANÇA NETO, J.B. (Ed.). Vigor de sementes: conceitos e testes. Londrina: ABRATES, 1999. p.71-74.

FREITAS, R.A., DIAS, D.C.F.S., CECON, P.R., REIS, M.S. Qualidade fisiológica e sanitária de sementes de algodão durante o armazenamento. Revista Brasileira de Sementes, Brasília, v.22, n.2, p.94-101, 2000.

FREITAS, R.A., DIAS, D.C.F.S., CECON, P.R., REIS, M.S. Storability of cotton seeds predicted by vigour tests. Seed Science and Technology, Zürich, v.30, n.2, p.403410, 2002.

INSTITUTO ADOLFO LUTZ. Normas analíticas do Instituto Adolfo Lutz; métodos químicos e físicos para análise de alimentos. 3 ed. São Paulo, 1985, v.1, 533p.

KAKADE, M.L., RACKIS, J.J., McGHEE, J.E., PUSKI, G. Determination of trypsin inhibitor activity of soy products: a collaborative analysis of an improved procedure. Cereal Chemistry, Sant Paul, v.51, n.51, p.376-382, 1974.

MACHADO NETO, N.B., CUSTÓDIO, C.C., TAKAKI, M. Evaluation of naturally and artificially aged seeds of Phaseolus vulagris L. Seed Science and Technology, Zürich, v.29, n.1, p.137-149, 2001.

MAHALANOBIS, P.C. On the generalized distance in statistics. Proceedings of National Institute of Science, v.12, p.49-55, 1936.

MAIA, F.C., MORAES, D.M., MORAES, R.C.P. Atividade total da fosfatase ácida e da $\alpha$-amilase induzidas por ácido jasmônico em sementes de soja. Revista Brasileira de Sementes, Brasília, v.22, n.1, p.259-263, 2000.

MARCOS FILHO, J. Teste de envelhecimento acelerado. In: KRZYZANOWSKI, F.C., VIEIRA, R.D., FRANÇA NETO, J.B. (Ed.). Vigor de sementes: conceitos e testes. Londrina: ABRATES, 1999. p.3.1-3.24. 
McDONALD JR., M.B. Seed deterioration: physiology, repair and assessment. Seed Science and Technology, Zürich, v.27, n.1, p.177-237, 1999.

MEDEIROS FILHO, S., FRAGA, A.C., QUEIROGA, V.P., SOUSA, L.C.F. Efeito do armazenamento sobre a qualidade fisiológica de sementes deslintadas de algodão. Ciência e Agrotecnologia, Lavras, v.20, n.3, p.284-292, 1996.

PÁDUA, G.P., VIEIRA, R.D. Deterioração de sementes de algodão durante o armazenamento. Revista Brasileira de Sementes, Brasília, v.23, n.2, p.255-262, 2001.

PÁDUA, G.P., VIEIRA, R.D., BARBOSA, J.C. Desempenho de sementes de algodão tratadas quimicamente e armazenadas. Revista Brasileira de Sementes, Brasília, v.24, n.1, p.212-219, 2002.

PAOLINELLI, G.P., BRAGA, S.J. Alterações da qualidade de sementes de algodão armazenadas com dois níveis de vigor. In: CONGRESSO BRASILEIRO DE SEMENTES, 10, 1997, Foz do Iguaçu. Resumos... Brasília: ABRATES, 1997. p.168.
SMITH, P.K., KRHON, R.I., HERMASON, G.T., MALLIA, A.K., GARDNER, F.H., PROVENZANO, M.D., FUJIMOTO, E.K., GOEKE, N.M., OLSON, B.J., KLENK, D.C. Measurement of protein using bicinchoninic acid. Analytical Biochemistry, New York, v.150, p.76-85, 1985.

SPINOLA, M.C.M., CÍCERO, S.M., MELO, M. Alterações bioquímicas e fisiológicas em sementes de milho causadas pelo envelhecimento acelerado. Scientia Agrícola, Piracicaba, v.57, n.2, p.263-270, 2000.

VIEIRA, M.G.G.C. Utilização de marcadores moleculares no monitoramento da qualidade sanitária e nível de deterioração de sementes de algodoeiro (Gossypium hirsutum L.). Lavras. 1996. 114f. Tese (Doutorado em Fitotecnia). Universidade Federal de Lavras, 1996.

VIEIRA, R.D., KRZYZANOWSKI, F.C. Teste de condutividade elétrica. In: KRZYZANOWSKI, F.C., VIEIRA, R.D., FRANÇA NETO, J.B. (Ed.). Vigor de sementes: conceitos e testes. Londrina: ABRATES, 1999. p.4.1-4.26. 